\title{
NEW INEQUALITIES FOR THE VOLUME OF THE UNIT BALL IN $\mathbb{R}^{n}$
}

\section{TAO BAN AND CHAO-PING CHEN}

Abstract. Many interesting monotonicity properties and inequalities for the volume of the unit ball in $\mathbb{R}^{n}$ have been established. The main object of this paper is to establish new inequalities for the volume of the unit ball in $\mathbb{R}^{n}$. Mathematics subject classification (2010): 33B15, 26D07.

Keywords and phrases: Volume of the unit $n$-dimensional ball, gamma function, inequality.

\section{REFERENCES}

[1] M. Abramowitz And I. A. Stegun (Eds.), Handbook of Mathematical Functions with Formulas, Graphs, and Mathematical Tables, National Bureau of Standards, Applied Mathematics Series 55, 9th printing, Dover, New York, 1972.

[2] H. Alzer, On some inequalities for the gamma and psi functions, Math. Comput. 66 (1997), 373-389.

[3] H. AlZER, Inequalities for the volume of the unit ball in $\mathbb{R}^{n}$, J. Math. Anal. Appl. 252 (2000), 353363.

[4] H. AlZER, Inequalities for the volume of the unit ball in $\mathbb{R}^{n}$, II, Mediterr. J. Math. 5 (2008), 395-413.

[5] G. D. Anderson, M. K. Vamanamurthy ANd M. Vuorinen, Special functions of quasiconformal theory, Exposition. Math. 7 (1989), 97-136.

[6] G. D. ANDERSON AND S.-L. QIU, A monotoneity property of the gamma function, Proc. Amer. Math. Soc. 125 (1997), 3355-3362.

[7] J. BÖHM AND E. HeRTEl, Polyedergeometrie in n-dimensionalen Räumen konstanter Krmmung, Birkhäuser, Basel, 1981.

[8] K. H. Borgwardt, The Simplex Method, Springer, Berlin, 1987.

[9] C.-P. CHEN AND R. B. PARIS, Inequalities, asymptotic expansions and completely monotonic functions related to the gamma function, Appl. Math. Comput. 250 (2015), 514-529.

[10] C.-P. CHEN AND R. B. PARIS, Inequalities, asymptotic expansions and completely monotonic functions related to the gamma function, Appl. Math. Comput. 250 (2015), 514-529.

[11] C.-P. CHEN AND L. Lin, Inequalities for the volume of the unit ball in $\mathbb{R}^{n}$, Mediterr. J. Math. 11 (2014), 299-314.

[12] B.-N. GUO AND F. QI, Monotonicity and logarithmic convexity relating to the volume of the unit ball, Optim. Lett. 7 (2013), 1139-1153.

[13] D. A. Klain And G.-C. Rota, A continuous analogue of Sperner's theorem, Comm. Pure Appl. Math. 50 (1997), 205-223.

[14] L. Lin, Further refinements of Gurland's formula for $\pi$, J. Inequal. Appl. 2013, 2013: 48, doi:10.1186/1029-242X-2013-48.

[15] Y. L. LuKE, The Special Functions and their Approximations, vol. I, Academic Press, New York, 1969.

[16] M. MerkLE, Gurland's ratio for the gamma function, Comp. Math. Appl. 49 (2005), 389-406.

[17] C. MorTiCI, Monotonicity properties of the volume of the unit ball in $\mathbb{R}^{n}$, Optim. Lett. 4 (2010), 457-464.

[18] C. MorTici, Series associated to some expressions involving the volume of the unit ball and applications, Appl. Math. Comput. 294 (2017), 121-138.

[19] S.-L. QIU AND M. VuORInEn, Some properties of the gamma and psi functions, with applications, Math. Comput. 74 (2004), 723-742. 